\title{
CHANGE OF ADDRESS
}

From June 1, 1969, the address of the Internationaal Instituut voor Sociale Geschiedenis as well as of the Editorial Board of the International Review of Social History will be:

Herengracht 262-266, Amsterdam, tel. 020/246671. 